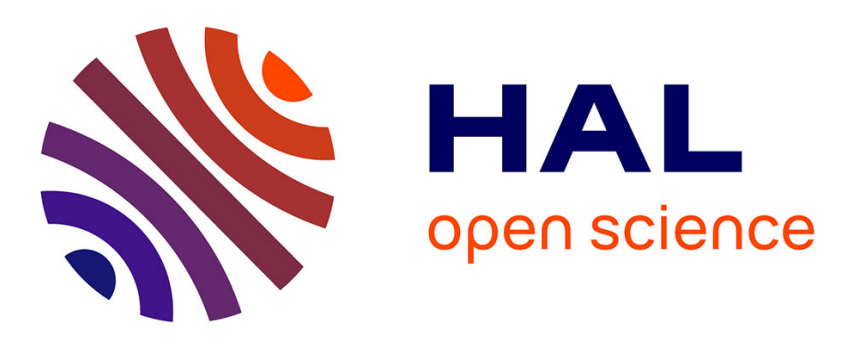

\title{
Prospective Longitudinal Study of Quality of life following cytoreductive surgery and intraperitoneal chemotherapy for pseudomyxoma peritonei
}

Suzanne Alves, Faheez Mohamed, Ghasem Yadegarfar, Haney Youssef, Brendan J. Moran

\section{To cite this version:}

Suzanne Alves, Faheez Mohamed, Ghasem Yadegarfar, Haney Youssef, Brendan J. Moran. Prospective Longitudinal Study of Quality of life following cytoreductive surgery and intraperitoneal chemotherapy for pseudomyxoma peritonei. EJSO - European Journal of Surgical Oncology, 2010, 36 (12), pp.1156. 10.1016/j.ejso.2010.09.004 . hal-00638136

\section{HAL Id: hal-00638136 https://hal.science/hal-00638136}

Submitted on 4 Nov 2011

HAL is a multi-disciplinary open access archive for the deposit and dissemination of scientific research documents, whether they are published or not. The documents may come from teaching and research institutions in France or abroad, or from public or private research centers.
L'archive ouverte pluridisciplinaire HAL, est destinée au dépôt et à la diffusion de documents scientifiques de niveau recherche, publiés ou non, émanant des établissements d'enseignement et de recherche français ou étrangers, des laboratoires publics ou privés. 


\section{Accepted Manuscript}

Title: Prospective Longitudinal Study of Quality of life following cytoreductive surgery and intraperitoneal chemotherapy for pseudomyxoma peritonei

Authors: Suzanne Alves, RGN, RCNT, RNT, BA, MSc Faheez Mohamed, MD, FRCSEd (Gen Surg) Ghasem Yadegarfar, MSc, PhD Haney Youssef, FRCS (Gen

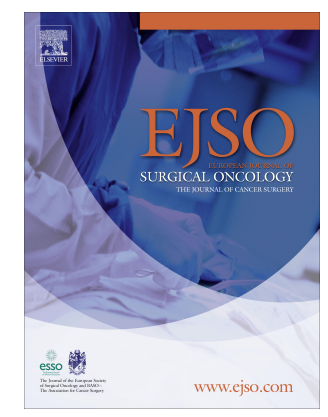
Surg) Brendan J. Moran, MCh, FRCS

PII:

S0748-7983(10)00503-2

DOI:

10.1016/j.ejso.2010.09.004

Reference: $\quad$ YEJSO 3044

To appear in: European Journal of Surgical Oncology

Received Date: 3 May 2010

Revised Date: 22 August 2010

Accepted Date: 2 September 2010

Please cite this article as: Alves S, Mohamed F, Yadegarfar G, Youssef H, Moran BJ. Prospective Longitudinal Study of Quality of life following cytoreductive surgery and intraperitoneal chemotherapy for pseudomyxoma peritonei, European Journal of Surgical Oncology (2010), doi: 10.1016/ j.ejso.2010.09.004

This is a PDF file of an unedited manuscript that has been accepted for publication. As a service to our customers we are providing this early version of the manuscript. The manuscript will undergo copyediting, typesetting, and review of the resulting proof before it is published in its final form. Please note that during the production process errors may be discovered which could affect the content, and all legal disclaimers that apply to the journal pertain. 
Title:

Authors:

Institution:

Corresponding author:

Category:

Original paper

UK
Prospective Longitudinal Study of Quality of life following cytoreductive surgery and intraperitoneal chemotherapy for pseudomyxoma peritonei

Suzanne Alves a , RGN, RCNT, RNT, BA, MSc

Faheez Mohamed ${ }^{\text {a }}$, MD, FRCSEd (Gen Surg)

Ghasem Yadegarfar $^{\mathrm{a} \& \mathrm{~b}}, \mathrm{MSc}, \mathrm{PhD}$

Haney Youssef ${ }^{\text {a }}$, FRCS (Gen Surg)

Brendan J. Moran ${ }^{\mathrm{a}}$, MCh, FRCS

${ }^{\mathrm{a}}$ Pseudomyxoma Peritonei Centre

Basingstoke and North Hampshire Hospital Foundation Trust

Aldermaston Road

BASINGSTOKE

Hampshire, RG24 9NA

${ }^{\mathrm{b}}$ School of Public Health Sciences

Isfahan University of Medical Sciences

Isfahan, IRAN

Mr Brendan Moran

Pseudomyxoma Peritonei Centre

Basingstoke and North Hampshire Hospital Foundation Trust

Aldermaston Road, Basingstoke

Hampshire, RG24 9NA

Tel: 01256313436

Fax: 01256336556

e-mail: Brendan.Moran@bnhft.nhs.uk 


\section{Abstract}

\section{Background}

Pseudomyxoma peritonei (PMP) is characterized by mucinous ascites, predominantly arising form a perforated tumour of the appendix. This study aimed to assess health related quality of life (HRQL) in patients following cytoreductive surgery and intraperitoneal chemotherapy for PMP.

\section{Methods}

Over a two year period, 49 consecutive patients (13 male, 36 females) with a median age of 55 (range 37 to 81 years) were enrolled. Patients were asked to complete the European Organization for Research and Treatment of Cancer (EORTC) QLQ-C30 questionnaire prior to surgery and at one, three, six and twelve months post-operatively.

\section{Results}

26 patients $(53 \%)$ underwent complete cytoreduction and $20(42 \%)$ patients had major tumour debulking. One patient died from progressive disease three months from surgery and two patients withdrew from the study within 6 months of surgery. Baseline questionnaire compliance was 100 per cent and remained high (overall $98 \%$ of eligible patients) during follow up .Grade III/IV morbidity occurred in 4 patients (9\%). Patients undergoing both complete cytoreduction and major tumour debulking reported a clinically significant improvement in emotional wellbeing, appetite and global HRQL at 1 year following surgery.

\section{Conclusion}

Despite the high morbidity associated with cytoreductive surgery and intraperitoneal chemotherapy, an improvement in quality of life at 1 year following the procedure was seen 
following both complete cytoreduction and major tumour debulking. Longer term assessment is required to demonstrate the durability of this enhancement.

Keywords: $\quad$ Appendiceal malignancy, cytoreductive surgery, hyperthermic intraperitoneal chemotherapy, quality of life 


\section{Introduction}

Increasingly it is recognised that quality of life is an important tool in assessing the benefits of therapeutic interventions, all of which have potential complications and side-effects. Patients and clinicians strive to balance benefit against risk, though in many instances neither the natural history of an untreated condition or the effects on the individual of a particular treatment are accurately known. At first glance, one might consider that life-prolonging therapies require little deliberation. However, some patients may feel that the ongoing suffering and loss of autonomy associated with intervention interferes with their ability to experience and live their remaining life and may refuse treatments with a potential life prolonging effect. Quality of life rather than length of survival becomes a key consideration.

Pseudomyxoma peritonei (PMP) has a reported incidence of approximately one to two per million per year [1,2] and is characterised by the accumulation of gelatinous fluid and mucinous implants on the peritoneal surface of the abdominal viscera. The term 'Jelly Belly' has been used to describe the large volume of mucinous ascites, that over time, fills the peritoneal cavity [3]. PMP has generally been considered a benign condition, but its behaviour suggests that it should always be considered, at best, a 'borderline malignant' condition with inevitable disease persistence and progression. The long-term survival in most patients with PMP remains poor with a reported 5 and 10 year survival rate of 50 and 30 per cent respectively[4].

The traditional treatment of PMP involves debulking to remove as much of the mucinous ascites as possible, usually combined with omentectomy and oophorectomy in women. Debulking is repeated as required but becomes less effective and more dangerous due to risks of inadvertent bowel injury. Death is usually due to malnutrition or complications of surgery, such as sepsis and intestinal fistulation. Progressive unrelenting abdominal distension results 
in respiratory compromise, gastro-oesophageal reflux, nausea, vomiting, anorexia, abdominal bloating and variable degrees of constipation and diarrhoea. Many of these symptoms are difficult to alleviate and the slowly expanding, locally progressive but otherwise nonmetastatic tumour, culminates in a distressing death, often after many months or years.

Recently Sugarbaker has proposed an aggressive combined treatment approach of cytoreductive surgery (CRS), with heated intraperitoneal chemotherapy (HIPEC) [5] [6] . We have reported our experience with similar results and projected 5 and 10 year disease free survival rates of $70-80 \%$ in favourable cases of PMP [7].

Although health related quality of life (HRQL) and functional status has been widely studied for common cancers, such information for rare diseases such as PMP is sparse. With the novel approaches to the management of PMP, and related peritoneal malignancies, and the general consensus that quality of life documentation is a key aspect in the evaluation of treatment for cancer, these issues need assessment in patients with PMP.

The European Organisation for the Research and Treatment of Cancer (EORTC) has been pivotal in developing tools for QoL assessment in patients with cancer. The core QLQ-C30 questionnaire is a useful basic instrument and the EORTC has produced rigorous guidelines for developing disease specific modules to supplement the QLC-C30. Examples in common use include modules for breast cancer (QLQ BR23), colorectal cancer (QLQ CR38) and pancreatic cancer (QLQ PAN 26).

A number of recent studies have described patient-rated and HRQL related outcomes following cytoreductive surgery and HIPEC for peritoneal surface malignancy[8-11]. However none are prospective and longitudinal in design. This study reports pre and postoperative Quality of life in consecutive patients undergoing laparotomy for PMP. 


\section{Patients and Methods}

Ethical approval was obtained from the local hospital ethics committee. Forty nine consecutive patients admitted for surgery at the North Hampshire Hospital in Basingstoke between 2003 and 2005 were identified by the specialist nurse and approached for study participation. This was a consecutive series of patients with PMP who had either complete macroscopic tumour removal by cytoreductive surgery (CRS) combined with heated intraperitoneal chemotherapy (HIPEC) $(n=26)$ or maximal tumour removal in the 20 where complete CRS was not achievable.

The inclusion criteria were that all patients should have a life expectancy of more than three months, be able to fully understand English, have no previous or concurrent malignancy, and should be physically and emotionally able to participate. All had to be aware of their diagnosis of PMP and be over the age of eighteen.

All patients received a detailed information leaflet outlining the study details, a questionnaire and a consent form. This was followed up by a telephone call after four days or face to face at a scheduled outpatient clinic appointment. All patients were given an identification code identifiable only by the primary researcher.

\section{Surgery and HIPEC}

26 patients underwent complete CRS and HIPEC and 20 had maximal tumour debulking (Table 1). The techniques have been previously described [7]. In total 29 patients received intra-operative, intraperitoneal, Mitomycin C $(10 \mathrm{mg} / \mathrm{m} 2)$ for 1 hour at $42 \mathrm{C}$. In addition 26 Patients received additional early post-operative $5 \mathrm{FU}(15 \mathrm{mg} / \mathrm{kg})$ for the first 4 postoperative days. Patients were routinely managed in the intensive care unit after surgery for a median of 2 days prior to transfer back to the ward. 


\section{Health Related Quality of life assessment}

Patients were asked to complete the European Organization for Research and Treatment of Cancer (EORTC) QLQ-C30 questionnaire [12] on five separate occasions, namely prior to surgery and at one, three, six and twelve months post-operatively. The EORTC QLQ-C30 contains scales and items addressing functional aspects of HRQL and symptoms that commonly occur in patients with cancer as well as items assessing the financial impact of malignant disease and global HRQL. There are five functional scales (physical, role, emotional, cognitive and social), three symptom scales (fatigue, nausea or vomiting, and pain) six single items (sleeping disorders, appetite loss, dyspnoea, diarrhoea, constipation and financial problems) and one global HRQL scale. Each item had four response alternatives (1, not at all; 2, a little; 3, quite a bit; 4, very much) and the global quality of life scale had a seven-step scale ranging from very poor to excellent.

\section{Statistical analysis}

Data were analysed using SPSS ${ }^{\circledR}$ for Windows version 17 (SPSS, Chicago, Illinois, USA). All questionnaire responses were transformed linearly into scores on a 0-100 scale according to the EORTC QLQ C-30 scoring manual [13]. High scores on both functional scales and the global HRQL scale represented a high level of function and better quality of life respectively. A high score on symptom scales and items suggested increased symptoms. Mean scores with 95\% confidence intervals were calculated. Based on previous research [14], a difference of at least 10 mean score points between time points was considered clinically relevant, and a difference of 5-10 was considered weak. Survival curves were calculated from the time of surgery according to the Kaplan-Meier method using the entire patient population. 


\section{Results}

Over the 2 year period from 2003 to 2005,49 patients (13 male, 36 females) with a median age of 55 (range 37 to 81 years) were enrolled. One patient died from progressive disease three months from surgery and two patients withdrew from the study within 6 months of surgery. An end ileostomy was fashioned in 11 patients and a loop ileostomy in 4 . The loop ileostomy was reversed between three and six months after primary surgery following a water soluble contrast enema to confirm anastomotic integrity. Where relevant, questionnaires were completed prior to stoma reversal to reduce confounding variables. Three patients with ovarian carcinomatosis and one with peritoneal mesothelioma underwent surgery during the 2 year study period but were not included. Baseline questionnaire compliance was 100 per cent and remained high (overall 98\% of eligible patients) during follow up.

\section{Morbidity and mortality}

Complications were graded according to National Cancer Institute Common Terminology Criteria for Adverse events (CTCAE) v3.0. Grade III/IV morbidity occurred in 4 patients (9\%).The most significant complication was a gastointestinal anastomotic leak in a patient who had a complete cytoreduction. The other 3 patients requiring intervention had an intraabdominal abscess which required percutaneous drainage under radiological guidance. There was no post-operative mortality.

\section{Global Health Related Quality of Life (HRQL) and Functional scales}

Just under $90 \%$ of the debulking group and $95 \%$ of patients undergoing complete cytoreduction were alive one year following their surgery. At 12 months from surgery there was no deterioration in functional scale measures from pre-operative baseline values. Patients 
who underwent major tumour debulking reported the most marked improvements in role, emotional, cognitive and social abilities. Both groups reported a clinically significant improvement in their global HRQL at 1 year (Fig 1). Following an initial drop in Global HRQL 1 month postoperatively, both groups reported return to preoperative levels at 3 months. This improvement continued to 12 months for patients undergoing complete cytoreduction, but remained relatively static for those who had major tumour debulking (table 2).

\section{Symptom scales}

The only clinically significant improvement in pre-operative symptoms was seen in pain reported at 1 year in the complete cytoreduction group (fig 2). Symptoms of pain did not improve in patients who had major tumour debulking with similar levels reported throughout the study period. Symptoms of fatigue and nausea or vomiting showed little improvement over the 12 months following surgery for most patients with marked worsening of symptoms in the first month.

\section{Single item scale}

Improvement in appetite was clinically significant at 1 year after surgery for all patients. Interestingly patients who underwent debulking had more problems with diarrhoea (Fig 3). The cause of this is uncertain but may include the extent of disease on the small bowel which is the main factor preventing complete tumour removal such that intestinal transit and/or fluid absorption are impaired. This requires further evaluation. Patients who had a complete cytoreduction reported a marked improvement in their ability to sleep in contrast to those whose tumour was debulked. 


\section{Discussion}

The optimal treatment of PMP involves extensive cytoreductive surgery (Table 1) and intraperitoneal chemotherapy with a five year survival rate of 70 to $80 \%$ [15-19]. However this complex treatment may impact significantly on the patients quality of life, especially the many in whom complete tumour removal is not achieved. If complete cytoreduction is not possible there is increasing evidence that maximal tumour debulking surgery offers relief from abdominal distension and nutritional symptoms for a considerable period of time. Survival of $43 \%$ at 2 years and 15\% at 5 years can be achieved [20] [21]. Maximal tumour debulking can usually be achieved by an extended right hemicolectomy, greater omentectomy and splenectomy with an ileocolic anastomosis, or alternatively a total colectomy and permanent ileostomy.

It is notable that for patients who underwent maximal tumour debulking, pain remained a persistent problem postoperatively for the period of our study. Patients who had complete cytoreduction had significant improvement in pain scores at 3 months with deterioration at 6 months but improvement beyond baseline at 12 months (Fig 2). More attention to symptom control may be required for those patients who have palliative tumour resection. Similarly the significant problems with diarrhoea in patients who had maximal tumour debulking suggests that a total colectomy and permanent ileostomy should be considered as the optimal treatment of this group and our surgical strategy has altered accordingly.

A number of recent studies have shown that after an initial decline in physical well-being and function after CRS with HIPEC there is a return to pre treatment levels of mental and physical well-being for most patients despite the aggressive multi-modality therapy. McQuellon and 
colleagues reported the health outcomes of 58 patients who underwent CRS with HIPEC for disseminated peritoneal cancer of appendiceal origin [10]. Quality of life returned to baseline levels at 1 year after surgery although depressive symptoms and some physical limitations did persist for some patients. Jess and colleagues [11] showed relatively little impact on quality of life in 23 patients with PMP despite the significant morbidity associated with CRS and perioperative intraperitoneal chemotherapy (PIC). Using a generic quality of life questionnaire (SF 36) the scores of patients were similar to the normal population at 6 months following surgery. Two other studies by McQuellon reported the short-term and long-term quality of life outcomes in patients who underwent CRS and intraperitoneal chemotherapy for peritoneal carcinomatosis, including PMP [8] [9]. Sixty four patients in the short-term study had decreased overall quality of life after surgery compared with baseline, but then returned to baseline or better within 3 to 6 months of surgery. A follow-up study of seventeen 3-yearsurvivors demonstrated that more than $90 \%$ of patients had minimal to no limitations of activity and had functional assessments that compared favourably with national reference values for their respective age groups.

Our study mirrors these findings and although quality of life was decreased compared to baseline 1 month after surgery, by three months it had returned to baseline levels, and continued to improve beyond baseline levels up to 12 months after surgery. The fact that patients reported a better quality of life at 1 year following surgery provides a strong argument for this combined surgical approach. Longer term assessment is needed to demonstrate durability of this enhanced quality of life and long term follow up in this group of patients is currently planned. Quality of life is an important parameter in pseudomyxoma peritonei, a rare, debilitating though eminently treatable condition with a complex approach combining extensive surgery and intraperitoneal chemotherapy. 


\section{Conflict of Interest Statement}

The authors declare no conflict of interest.

\section{Funding Source}

This study was supported by funding from the National Commissioning Group (NCG) of the National Health Service, UK. Although NCG provide funding for the Pseudomyxoma service at the North Hampshire Hospital they had no involvement in this study. 


\section{References}

1. National Institute for Health and Clinical Excellence (NICE). Complete cytoreduction for pseudomyxoma peritonei (SugarbakerTechnique) 2004. http://www.nice.org.uk/Guidance/IPG56

2. Smeenk RM, van Velthuysen ML, Verwaal VJ, Zoetmulder FA: Appendiceal neoplasms and pseudomyxoma peritonei: a population based study. Eur J Surg Oncol 2008;34:196-201.

3. Moran BJ, Cecil TD: The etiology, clinical presentation, and management of pseudomyxoma peritonei. Surg Oncol Clin N Am 2003;12:585-603.

4. Hinson FL, Ambrose NS: Pseudomyxoma peritonei. Br J Surg 1998;85:1332-1339.

5. Sugarbaker PH, Kern K, Lack E: Malignant pseudomyxoma peritonei of colonic origin. Natural history and presentation of a curative approach to treatment. Dis Colon Rectum 1987;30:772-779.

6. Sugarbaker PH: Surgical treatment of peritoneal carcinomatosis: $1988 \mathrm{Du}$ Pont lecture. Can J Surg 1989;32:164-170.

7. Moran BJ, Mukherjee A, Sexton R: Operability and early outcome in 100 consecutive laparotomies for peritoneal malignancy. Br J Surg 2006;93:100-104.

8. McQuellon RP, Loggie BW, Fleming RA, et al.: Quality of life after intraperitoneal hyperthermic chemotherapy (IPHC) for peritoneal carcinomatosis. Eur J Surg Oncol 2001;27:65-73.

9. McQuellon RP, Loggie BW, Lehman AB, et al.: Long-term survivorship and quality of life after cytoreductive surgery plus intraperitoneal hyperthermic chemotherapy for peritoneal carcinomatosis. Ann Surg Oncol 2003;10:155-162.

10. McQuellon RP, Russell GB, Shen P, et al.: Survival and health outcomes after cytoreductive surgery with intraperitoneal hyperthermic chemotherapy for disseminated peritoneal cancer of appendiceal origin. Ann Surg Oncol 2008;15:125133.

11. Jess P, Iversen LH, Nielsen MB, et al.: Quality of life after cytoreductive surgery plus early intraperitoneal postoperative chemotherapy for pseudomyxoma peritonei: a prospective study. Dis Colon Rectum 2008;51:868-874.

12. Aaronson NK, Ahmedzai S, Bergman B, et al.: The European Organization for Research and Treatment of Cancer QLQ-C30: a quality-of-life instrument for use in international clinical trials in oncology. J Natl Cancer Inst 1993;85:365-376. 
13. Fayers PM, Aaronson N.K., Bjordal K., Curran D, Groenvold M.: EORTC QLQ-C30 Scoring Manual (2nd edition). InBrussels, 1999.

14. Osoba D, Rodrigues G, Myles J, et al.: Interpreting the significance of changes in health-related quality-of-life scores. J Clin Oncol 1998;16:139-144.

15. Yan TD, Links M, Xu ZY, et al.: Cytoreductive surgery and perioperative intraperitoneal chemotherapy for pseudomyxoma peritonei from appendiceal mucinous neoplasms. Br J Surg 2006;93:1270-1276.

16. Smeenk RM, Verwaal VJ, Antonini N, Zoetmulder FA: Survival analysis of pseudomyxoma peritonei patients treated by cytoreductive surgery and hyperthermic intraperitoneal chemotherapy. Ann Surg 2007;245:104-109.

17. Baratti D, Kusamura S, Nonaka D, et al.: Pseudomyxoma peritonei: clinical pathological and biological prognostic factors in patients treated with cytoreductive surgery and hyperthermic intraperitoneal chemotherapy (HIPEC). Ann Surg Oncol 2008; $15: 526-534$.

18. Murphy EM, Sexton R, Moran BJ: Early results of surgery in 123 patients with pseudomyxoma peritonei from a perforated appendiceal neoplasm. Dis Colon Rectum 2007;50:37-42.

19. Elias D, Honore C, Ciuchendea R, et al.: Peritoneal pseudomyxoma: results of a systematic policy of complete cytoreductive surgery and hyperthermic intraperitoneal chemotherapy. Br J Surg 2008;95:1164-1171.

20. Stewart JHt, Shen P, Russell GB, et al.: Appendiceal neoplasms with peritoneal dissemination: outcomes after cytoreductive surgery and intraperitoneal hyperthermic chemotherapy. Ann Surg Oncol 2006;13:624-634.

21. Glehen O, Mohamed F, Sugarbaker PH: Incomplete cytoreduction in 174 patients with peritoneal carcinomatosis from appendiceal malignancy. Ann Surg 2004;240:278-285. 
Table 1. Procedures performed

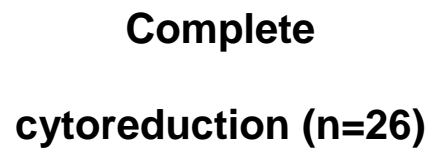

Subtotal/total colectomy

Anterior resection of rectum

lleostomy

Small bowel resection

Parietal peritonectomy

Liver capsulectomy

Stripping of hemidiaphragms

Pelvic peritonectomy

Splenectomy

Partial or total gastrectomy

Lesser omentectomy

Greater omentectomy

Cholecystectomy

Salpingo-oopherectomy

Total abdominal hysterectomy

HIPEC

EPIC 5FU
13

15

2

10

12

3

5

6

27 (18 right, 9 left)

18

18

4

20

25

25

11

10

26

26
12

17

2

3

3

6

14

3

2

2

1

2

1

5 (2 right, 3 left)

2

6

0

6

0

$\begin{array}{ll}\text { HIPEC } & \text { Hyperthermic Intraperitoneal Chemotherapy } \\ \text { EPIC 5FU } & \text { Early postoperative intraperitoneal chemotherapy } 5 \text { fluouracil }\end{array}$ 
Table 2. Mean related quality of life scores for complete cytoreduction and maximal tumour debulking before and after surgery.

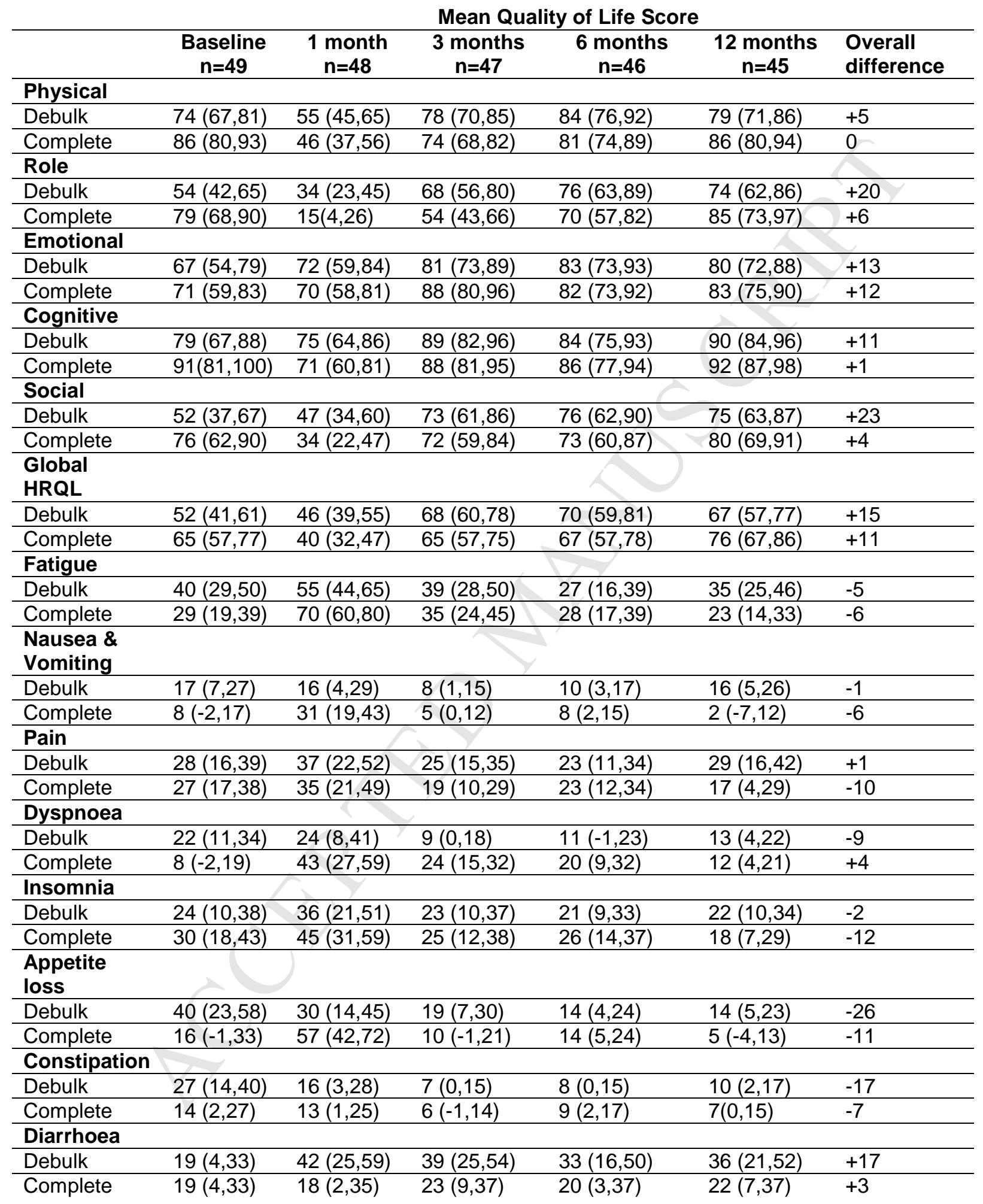

Values are Mean (95\% Confidence Interval). Scores range from 0 to 100. A higher score in the Function scales and the Global Health-related Quality of Life (HRQL) scale represents better quality of life or a higher level of functioning. A higher score for the Symptom scales represents more severe symptoms. Overall difference was calculated as the score at 12 months minus the baseline score 


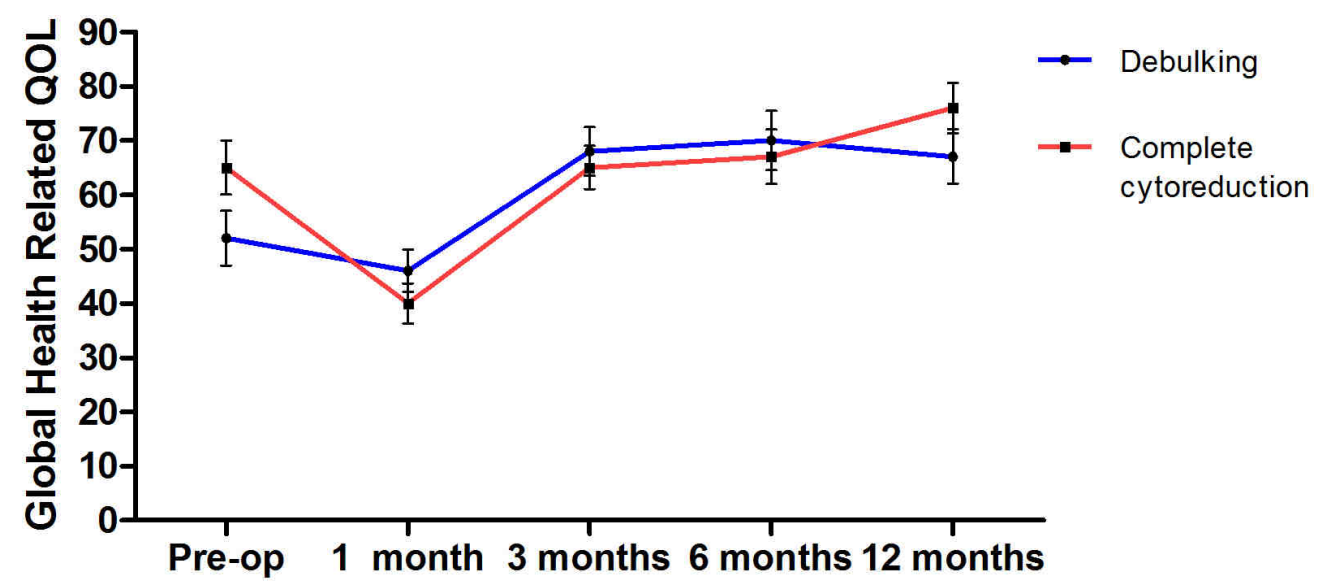




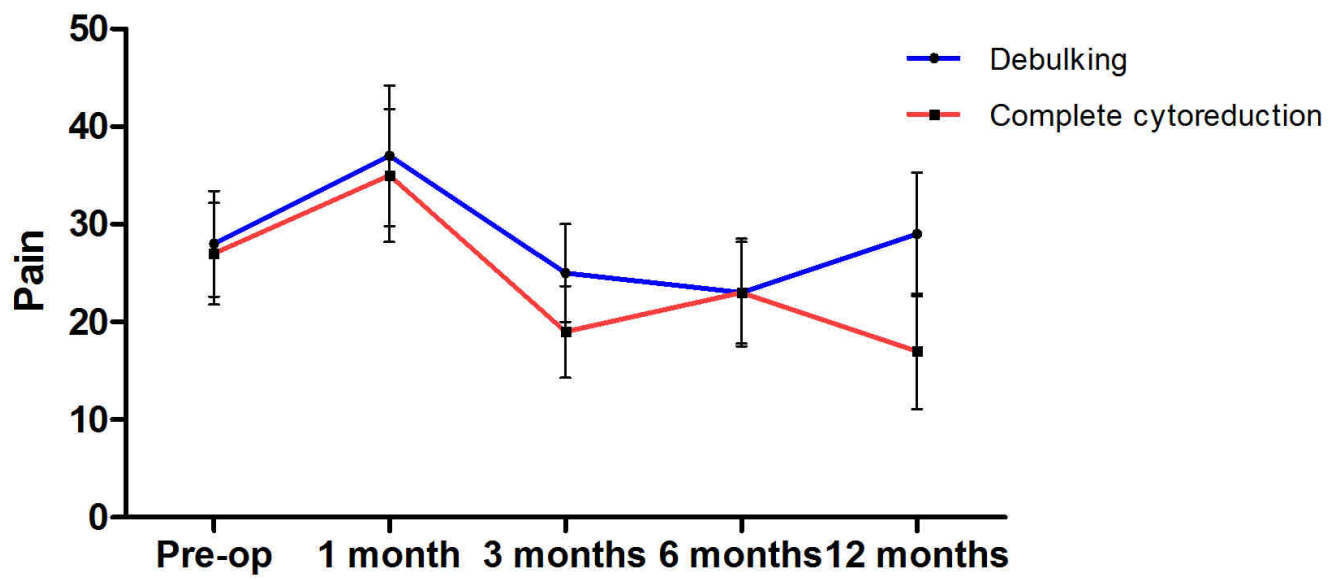




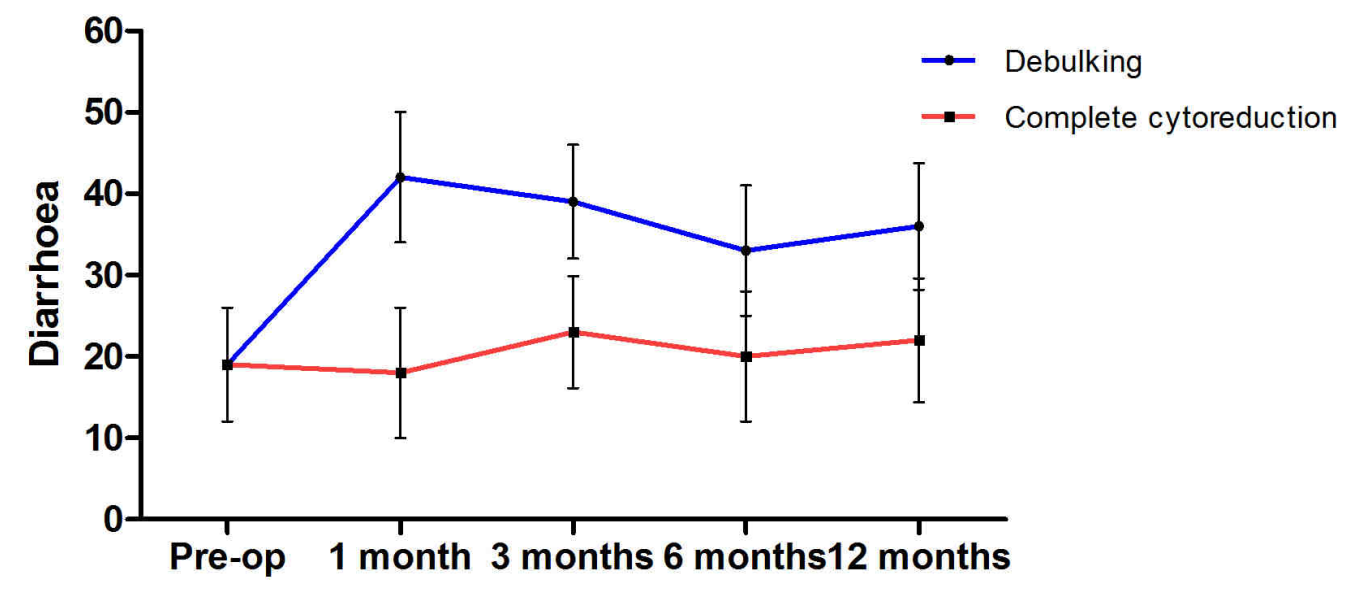

